\title{
Argamassas de cal para conservação e reabilitação de edifícios: conhecimento consolidado e necessidades de investigação
}

\author{
Lime mortars for building conservation and \\ rehabilitation: consolidated knowledge and research \\ needs
}

\begin{abstract}
Maria do Rosario Veiga
\section{Resumo}

A s argamassas de cal foram usadas na construção desde tempos imemoriais até pelo menos ao início do século XX. Em muitas regiões do mundo mantiveram um papel importante nos edifícios até à década de cinquenta do século passado. Este material pode, como talvez nenhum outro, contar a história da construção. Com o surgimento e rápida generalização do uso do cimento, começou a perder-se o conhecimento tradicional das técnicas da cal, que era transmitido diretamente através das gerações. Para recuperar esse conhecimento têm vindo a ser realizados numerosos estudos científicos, envolvendo a análise de argamassas antigas, o estudo de tratados antigos e a investigação sobre novas argamassas de cal. Apesar destes esforços, e das evidências de que as argamassas de cal são as mais adequadas para a conservação de edifícios antigos, continua a ser pouco frequente a sua utilização nas intervenções de conservação.O que falta saber para possibilitar a sua utilização generalizada? Quais as necessidades de investigação e de ação?

Palavras-chave: Argamassa de cal. Carbonatação. Técnicas de aplicação. Fatores de degradação. Necessidades de investigação.

\section{Abstract}

Lime mortars were used in construction from immemorial times until at least the beginning of the $20^{\text {th }}$ century. In many regions of the world they continued to have an important role in buildings until the 1950s. This material can tell the history of construction, as perhaps none other can. With the emergence and quick expansion of the use of cement, the traditional knowledge of lime techniques, which was directly transmitted across the generations, started to be lost. In order to recover the lost knowledge, a number of scientific studies were undertaken, involving the analysis of old mortars, the study of old treaties and research about new lime

${ }^{1}$ Maria do Rosario Veiga ${ }^{1}$ Laboratório Nacional de Engenharia

Civil

Libosa - Portugal

Recebido em 20/12/17 Aceito em 18/05/18 mortars. In spite of all those efforts, and the evidences that lime mortars are the most adequate for the conservation of old buildings, their use in conservation interventions is still rare. What is lacking in terms of knowledge in order to make their widespread use possible? Which are the main research and action needs?

Keywords: Lime mortar. Carbonation. Application techniques. Degradation factors. Research needs.
\end{abstract}




\section{Introdução}

As argamassas de cal foram usadas na construção desde tempos imemoriais até pelo menos ao início do século XX. Em muitos Países (como é o caso de Portugal), mantiveram um papel importante nos edifícios até à década de cinquenta do século XX (ALMEIDA et al., 2017). Este material pode, como talvez nenhum outro, contar a história da construção. No entanto, após o surgimento do cimento, bastaram algumas décadas para que as técnicas ligadas à preparação e aplicação de argamassas de cal fossem esquecidas. Quebrou-se a continuidade da sua transmissão direta de pais para filhos, de mestres para aprendizes; as técnicas da cal passaram a ser mistérios multifacetados que é necessário reaprender.

Para resolver essa descontinuidade de conhecimento, têm vindo a ser realizados, nas últimas quatro décadas, estudos científicos sobre a cal e as argamassas de cal, partindo da análise de argamassas antigas (MAGALHÃES; VEIGA, 2009; VELOSA et al., 2007; SILVA et al., 2011; PAPAYIANNI; STEFANIDOU, 2007) e do estudo de tratados antigos e prosseguindo com a investigação sobre novas argamassas de cal e a sua evolução no tempo. Foram estudadas profundamente a qualidade e as proporções dos materiais constituintes (CAZALLA et al., 2002; LANAS; ALVAREZ, 2003; PERONI et al., 1981; VEIGA et al., 2010) e as condições ambientais a garantir (LANAS; SIRERA; ALVAREZ, 2006;
PAVLÍK; UŽÁKOVÁ, 2016). Também a evolução da carbonatação e da estrutura porosa foi analisada (CIZER et al., 2012; ARANDIGOYEN et al., 2006; ARIZZI et al., 2011), assim como a influência dos modos de execução e de aplicação (CAVACO; VEIGA; GOMES, 2003; MARGALHA et al., 2011; BALKSTEN; KALSÉN, 2005; ROSELL et al., 2014) e das condições de produção da cal (CAZALLA et al., 2002; MARGALHA et al., 2013a; RODRIGUEZNAVARRO; HANSEN, 1998; HANSEN et al., 2000). Tais estudos foram divulgados em revistas da especialidade, livros, congressos e seminários.

Apesar destes esforços, e das evidências de que as argamassas de cal são, por razões éticas e técnicas, as mais adequadas para a conservação de edifícios antigos, a sua utilização nas intervenções de conservação e reabilitação é encarada com alguma desconfiança e continua a ser pouco frequente.

O que falta saber para possibilitar a sua utilização generalizada? E o que falta fazer?

\section{Composição das argamassas}

As argamassas com base em cal foram largamente usadas como materiais estruturais e de acabamento desde há mais de 10000 anos (BENTUR, 2002; LAWRENCE, 2006) até meados do século XX (Figura 1).

Figura 1 - Argamassas de cal de edifícios históricos: argamassas de pavimento da Villa romana de Pisões; revestimento de Igreja em Bolonha; assentamento de painel de azulejos em parede interior de um Palácio da região de Lisboa; parede de edifício com gaiola Pombalina, na Baixa de Lisboa
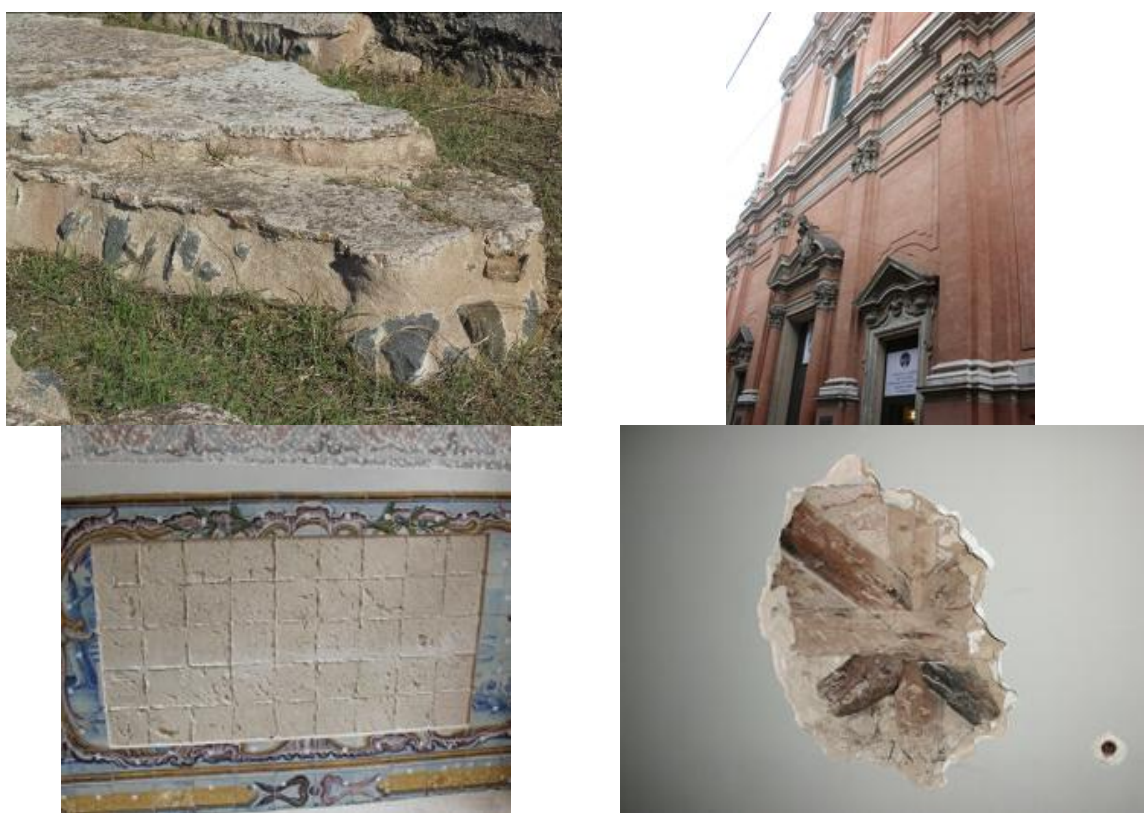

86 Veiga, M. R. 
As argamassas de edifícios históricos que chegaram aos nossos dias têm grande variedade de composições; são em geral ricas em ligante, com proporções volumétricas cal:agregado maioritariamente de cerca de 1:1 a 1:4 (VELOSA; VEIGA, 2016), encontrando-se habitualmente os traços mais ricos em edifícios considerados de maior importância e por isso de construção mais cuidada, como os edifícios militares, religiosos ou apalaçados.

Nestas argamassas antigas são em geral visíveis pequenos grânulos brancos de cal, por vezes atribuídas à utilização de cal viva mal apagada (método da cal viva apagada com areia, ou hot lime mix) mas podem também resultar de cal em pó ou em pasta mal misturada de origem, ou da repricipitação de carbonato de cálcio.

A proporção cal : agregado é um dos fatores que influenciam decisivamente as características e o comportamento das argamassas de cal e foi portanto um aspeto estudado desde que se reiniciou a investigação sobre as propriedades das argamassas de cal, com o objectivo de obter materiais compatíveis e adequados para conservação e restauro de edifícios históricos (CAZALLA et al., 2002; PERONI et al., 1981; VEIGA et al., 2010). O traço volumétrico 1:3 (cal aérea : areia) foi apontado como referência, por ser o traço indicado por Vitrúvio (RUA, 1998) embora estas indicações envolvam grande incerteza, considerando que provavelmente esta proporção se referia a cal em pasta e não a cal em pó, que o agregado podia incluir pozolanas e que as traduções do latim nem sempre são totalmente inequívocas. No entanto, este é também o traço que assegura, para uma areia bem graduada, o melhor preenchimento dos vazios da areia pela cal e, portanto, teoricamente, a melhor compacidade. Com efeito sabe-se que o índice de vazios de uma areia bem graduada é no mínimo de $33 \%$, enquanto uma areia mal graduada pode ter cerca de $48 \%$, o que levaria a um traço próximo de 1:2 para assegurar um bom preenchimento desses vazios (POPOVICS, 1992; GILLMORE, 2000). Nos últimos anos foram ensaiadas argamassas com traços semelhantes aos encontrados nos edifícios antigos, nomeadamente entre 1:1 e 1:4. Sintetizamse na Tabela 1 os resultados obtidos por alguns autores, em ensaios realizados com base em Normas Europeias, embora com adaptações para adequação a argamassas de cal (LANAS; ALVAREZ, 2003; VEIGA et al., 2010; BORSOI et al., 2012; PASCOAL et al., 2015; MARGALHA, 1997; FARIA-RODRIGUES,
2004; RAMALHO, 2013; HENRIQUES, 2005; FARIA; HENRIQUES; RATO, 2008; RATO, 2006; VEIGA; VELOSA; MAGALHÃES, 2009; STEFANIDOU; PAPAYIANNI, 2005).

$\mathrm{Na}$ Tabela 1, procurou-se apresentar os intervalos de variação de diversas características físicas e mecânicas de argamassas de cal aérea estudadas por diversos autores, assim como fazer a análise estatística possível dos resultados encontrados. No entanto deve ter-se em conta que alguns estudos tinham apenas parte dos valores em análise (por exemplo só parte dos traços ou só parte dos ensaios). Faz-se notar que os largos intervalos e elevados desvios-padrão reportados refletem a diversidade de matérias-primas usadas, principalmente no que diz respeito a agregados e a teores de água de amassadura.

Mesmo com estes fatores de variabilidade, os resultados tratados mostram que argamassas maispobres em cal (traço 1:4) têm as menores resistências mecânicas, mas que as mais ricas em cal (1:2 e 1:1) nem sempre são mais resistentes que as de traço $1: 3$ e podem ter maiores porosidades abertas e coeficientes de capilaridade superiores, pelo menos a curto prazo (90 dias).

A utilização de aditivos, quer minerais (por exemplo aditivos pozolânicos, microssílica, etc.), quer orgânicos (por exemplo, retentores de água, introdutores de ar, fibras orgânicas), resultam também em alterações de características, podendo melhorar o comportamento e a durabilidade (VELOSA; VEIGA, 2001; DI BELLA et al., 2014; DURAN et al., 2014; WALKER; PAVIA; MITCHELL, 2014; LIGUORI; CAPUTO; LUCOLANO, 2015). Assim, os aditivos pozolânicos conferem hidraulicidade e, portanto, favorecem a resistência à água, a nanosílica e os zeólitos conferem aumentos de resistência, as fibras reduzem a retração e a fissuração, os retentores de água reduzem o risco de dessecação e favorecem as reações pozolânicas, os introdutores de ar aumentam a deformabilidade e reduzem a vulnerabilidade ao gelo-degelo, mas reduzem a resistência mecânica. No entanto, a aplicação destes aditivos tem especificidades próprias, os seus efeitos dependem de proporções e de condições de cura adequadas. Por exemplo, a eficácia da adição de pozolanas artificiais, como o metacaulino, implica a existência de humidade relativa elevada durante um período inicial de cura, em simultâneo com a disponibilidade de um teor de cal livre suficiente para que a reação pozolânica seja efetiva (GAMEIRO et al., 2012). 
Tabela 1 - Intervalos de características mecânicas e físicas obtidas em ensaios de argamassas de cal e areia

\begin{tabular}{|c|c|c|c|c|c|c|}
\hline $\begin{array}{l}\text { Traço cal : areia } \\
\text { (volumé-trico) }\end{array}$ & & $\begin{array}{l}\text { Flexão } \\
90 \text { d } \\
\text { (MPa) }\end{array}$ & $\begin{array}{c}\text { Compressão } \\
90 \text { d } \\
(\mathrm{MPa})\end{array}$ & $\begin{array}{c}\text { Módulo de } \\
\text { Elasticidade } \\
90 \mathrm{~d} \\
(\mathrm{MPa})\end{array}$ & $\begin{array}{c}\text { Coeficiente de } \\
\text { Capilaridade } \\
90 \mathrm{~d} \\
\left(\mathbf{k g} /\left(\mathbf{m}^{2} \cdot \mathrm{min}^{1 / 2}\right)\right)\end{array}$ & $\begin{array}{c}\text { Porosidade } \\
\text { aberta }(\%)\end{array}$ \\
\hline \multirow{3}{*}{$\begin{array}{c}1: 4 \\
\text { Borsoi et al. }(2012), \\
\text { Pascoal et al. }(2015) \text { e } \\
\text { Lanas e Alvarez (2003) }\end{array}$} & Máx-Mín & $0,2-0,5$ & $0,3-1,5$ & - & - & - \\
\hline & Média & 0,4 & 0,9 & - & - & - \\
\hline & $\begin{array}{l}\text { Desvio- } \\
\text { padrão }\end{array}$ & 0,1 & 0,5 & - & - & - \\
\hline \multirow{3}{*}{$\begin{array}{c}1: 3 \\
\text { Margalha (1997), Faria- } \\
\text { Rodrigues (2004), } \\
\text { Marques et al. (2006), } \\
\text { Rato (2006), Guerreiro, } \\
\text { Henriques e Pinto } \\
\text { (2007), Veiga } \text { et al. } \\
\text { (2010) e Ramalho } \\
\text { (2013) }\end{array}$} & Máx-Mín & $0,2-0,8$ & $0,6-1,6$ & $2330-4440$ & $1,1-2,4$ & $27-35$ \\
\hline & Média & 0,4 & 1,1 & 306 & 1,7 & 33 \\
\hline & $\begin{array}{l}\text { Desvio- } \\
\text { padrão }\end{array}$ & 0,2 & 0,5 & 1121 & 0,5 & 4 \\
\hline \multirow{3}{*}{$\begin{array}{c}1: 2 \\
\text { Lanas e Alvarez (2003), } \\
\text { Marques et al. } \\
\text { (2006), Ramalho (2013), } \\
\text { Henriques (2005), } \\
\text { Faria, Henriques e Rato } \\
\text { (2008) e Stefanidou e } \\
\text { Papayianni (2005) }\end{array}$} & Máx-Mín & $0,3-0,6$ & $0,6-1,5$ & $2090-4710$ & $1,9-2,6$ & 28-39 \\
\hline & Média & 0,5 & 1,2 & 2913 & 2,3 & 34 \\
\hline & $\begin{array}{l}\text { Desvio- } \\
\text { padrão }\end{array}$ & 0,1 & 0,5 & 1240 & 0,5 & 5 \\
\hline \multirow{3}{*}{$\begin{array}{c}1: 1 \\
\text { Lanas e Alvarez (2003), } \\
\text { Marqueset al. (2006) e } \\
\text { Stefanidou e Papayianni } \\
\text { (2005) }\end{array}$} & Máx-Mín & $0,4-0,8$ & $1,1-2,0$ & 2860 & - & 34-50 \\
\hline & Média & 0,6 & 1,4 & 2860 & - & 39 \\
\hline & $\begin{array}{c}\text { Desvio- } \\
\text { padrão }\end{array}$ & 0,2 & 0,4 & - & - & 8 \\
\hline
\end{tabular}

Têm sido realizados vários estudos procurando determinar de que forma os modos de produção e de extinção da cal se refletem em alteração de características (MARGALHA et al., 2011; ROSELL et al., 2014; MARGALHA et al., 2013a, 2013b; FARIA-RODRIGUES, 2004). Nas Tabelas 2 e 3 apresentam-se alguns resultados que ilustram as variações de comportamento, retirados de estudos de MARGALHA (2010) e de FARIARODRIGUES (2004).

Os resultados recolhidos, e sintetizados na Tabela 2 , indicam que as argamassas com cais produzidas no forno artesanal de Montes Claros apresentam resultados um pouco inferiores às argamassas com cal de fabrico industrial com calcário da mesma região; no entanto, a variação é menos pronunciada que a resultante do uso de diferentes areias, como se pode ver pela comparação entre as argamassas de cal industrial com areias de Santa Margarida e de Sesimbra.

No que se refere aos modos de extinção os resultados da Tabela 3 mostram que a cal hidratada em pó, desde que bem extinta e com taxas reduzidas de carbonatação, origina argamassas com resultados médios de características mecânicas e reduzidos de capilaridade; enquanto as argamassas obtidas a partir de cal viva podem apresentar resultados superiores se a cal viva for usada sob a forma de cal viva micronizada, provavelmente por dessa forma facilitar uma hidratação mais rápida e uniforme; e as argamassas com cal em pasta apresentam resistências mecânicas inferiores e maior porosidade. É preciso ter em conta que os resultados apresentados são aos 90 dias, podendo haver alterações significativas a longo prazo. Com efeito, alguns estudos indicam que a cal em pasta com longos períodos de maturação (da ordem de 5 anos) pode conduzir a melhores resultados a longo prazo (MARGALHA et al., 2013b), devido à sua microestrutura e elevada reatividade.

Independentemente das características mecânicas, uma vantagem evidente da cal em pasta é a sua conservação ao longo do tempo de armazenagem sem carbonatação $\left(100 \% \mathrm{Ca}(\mathrm{OH})_{2}\right)$, portanto sem perda de reatividade. Também a boa trabalhabilidade e plasticidade são factores distintivos positivos, que recomendam esse material, principalmente para acabamentos decorativos. Estas características podem promover a redução da quantidade de água de amassadura, melhorando por essa via as características 
mecânicas, no entanto tal não ficou comprovado nos estudos analisados.

O agregado é um fator decisivo no bom comportamento das argamassas de cal, em termos de granulometria, de forma e de natureza mineralógica (ARIZZI et al., 2011; STEFANIDOU; $\quad$ PAPAYIANNI, 2005;
FRAGATA; VEIGA, 2010; SANTOS et al., 2015 ROMAGNOLI; RIVASI, 2007): uma areia bem graduada com granulometria extensa para garantir a melhor compacidade, uma boa proporção de grossos para assegurar boa resistência a longo prazo e uma natureza mineralógica que favoreça a ligação com a cal, são fatores essenciais.

Tabela 2 - Características mecânicas e físicas de argamassas obtidas com processos de produção artesanal versus industrial

\begin{tabular}{c|c|c|c|c|c}
\hline Cal & $\begin{array}{c}\text { Traço cal : } \\
\text { areia } \\
\text { (volumétrico) }\end{array}$ & $\begin{array}{c}\text { Flexão } \\
\mathbf{9 0} \\
\mathbf{d}(\mathbf{M P a})\end{array}$ & $\begin{array}{c}\text { Compressão } \\
\mathbf{9 0} \mathbf{d}(\mathbf{M P a})\end{array}$ & $\begin{array}{c}\text { Módulo de } \\
\text { Elasticidade 90 } \\
\mathbf{d}(\mathbf{M P a})\end{array}$ & $\begin{array}{c}\text { Coeficiente de } \\
\text { Capilaridade90 } \\
\mathbf{d}\left(\mathbf{k g} / \mathbf{m}^{\mathbf{2}} \cdot \mathbf{m i n}^{\mathbf{1 / 2}}\right) \text { ) }\end{array}$ \\
\hline MCp_G & $1: 3$ & 0,39 & 0,85 & 4070 & 0,77 \\
MCb_G & $1: 3$ & 0,33 & 0,63 & 3320 & 1,49 \\
I_G & $1: 3$ & 0,43 & 0,90 & 4400 & 1,08 \\
MCp_SM & $1: 3$ & 0,43 & 1,16 & - & 2,51 \\
MCb_SM & $1: 3$ & 0,28 & 0,69 & - & 1,00 \\
I_SM & $1: 3$ & 0,52 & 1,33 & 3890 & 0,77 \\
I_S & $1: 3$ & 0,37 & 1,30 & 3180 & 1,20 \\
\hline
\end{tabular}

Fonte: Margalha (2010)

Nota: Legenda:
MCp - Montes Claros preta;
MCb - Montes Claros branca;
I - Industrial;
G - Areia do rio Guadiana;
SM - Areia de Santa Margarida; e
$S$ - Areia de Sesimbra.

Tabela 3 - Características mecânicas e físicas de argamassas obtidas com diferentes modos de extinção

\begin{tabular}{|c|c|c|c|c|c|c|}
\hline Tipo de cal & $\begin{array}{c}\text { Traço } \\
\text { cal : areia } \\
\text { (volum.) } \\
\end{array}$ & $\begin{array}{l}\text { Flexão } \\
90 \text { d } \\
(\mathrm{MPa}) \\
\end{array}$ & $\begin{array}{c}\text { Compressão } \\
90 \text { d } \\
(\mathrm{MPa}) \\
\end{array}$ & $\begin{array}{l}\text { Módulo de } \\
\text { Elasticidade } \\
90 \text { d(MPa) }\end{array}$ & $\begin{array}{c}\text { Coeficiente de } \\
\text { Capilaridade } 90 \mathrm{~d} \\
\left.\left(\mathrm{~kg} / \mathrm{m}^{2} \cdot \mathrm{min}^{1 / 2}\right)\right)\end{array}$ & $\begin{array}{c}\text { Porosidade } \\
\text { aberta } \\
(\%) \\
\end{array}$ \\
\hline Cal em pó & $1: 3$ & 0,52 & 1,33 & - & 0,77 & - \\
\hline $\begin{array}{l}\text { Cal em pedra } \\
\text { extinta com } \\
\text { areia húmida } \\
\text { por } 1 \mathrm{~d}\end{array}$ & $1: 3$ & 0,47 & 0,96 & 3816 & 1,64 & - \\
\hline $\begin{array}{l}\text { Cal em pedra } \\
\text { extinta com } \\
\text { areia húmida } \\
\text { por } 7 \mathrm{~d}\end{array}$ & $1: 3$ & 0,50 & 1,08 & 3658 & 1,48 & - \\
\hline $\begin{array}{c}\text { Cal em pasta } 1 \\
\text { mes }\end{array}$ & $1: 3$ & 0,37 & 1,06 & 4091 & 1,47 & - \\
\hline $\begin{array}{c}\text { Cal em pasta } 5 \\
\text { anos }\end{array}$ & $1: 3$ & 0,63 & 1,42 & 4748 & 1,29 & - \\
\hline Cal em pó & $1: 2$ & 0,32 & 0,75 & 2100 & 0,4 & 35 \\
\hline $\begin{array}{c}\text { Cal viva } \\
\text { micronizada } \\
\text { extinta sob a } \\
\text { forma de pasta }\end{array}$ & $1: 2$ & 0,63 & 1,09 & 3100 & 0,3 & 37 \\
\hline $\begin{array}{c}\text { Cal em pasta } \\
\text { (16 meses) }\end{array}$ & $1: 2$ & 0,23 & 0,35 & 1600 & 1,2 & 40 \\
\hline
\end{tabular}

Fonte: Faria-Rodrigues (2004) e Margalha (2010). 


\section{Evolução da carbonatação e da estrutura porosa}

O endurecimento das argamassas de cal aérea dáse essencialmente por carbonatação da cal hidratada, ou seja, através da transformação do hidróxido de cálcio em carbonato de cálcio por reação com o dióxido de carbono do ar. De um modo simplificado, essa reacção pode exprimir-se pela seguinte equação química: $\mathrm{Ca}(\mathrm{OH})_{2}+\mathrm{CO}_{2} \rightarrow$ $\mathrm{CaCO}_{3}+\mathrm{H}_{2} \mathrm{O}$. No entanto, o processo é, na verdade, mais complexo e requer que o dióxido de carbono seja previamente dissolvido em água para que a reacção se desenvolva.

A carbonatação exige o contacto da argamassa com o $\mathrm{CO}_{2}$ e requer alguma humidade para permitir a dissolução deste gás; por outro lado, é necessário que os poros da argamassa não estejam saturados para existirem condições de difusão do $\mathrm{CO}_{2}$ dissolvido na rede porosa. Assim, as condições adequadas de humidade relativa são intermédias, situando-se aproximadamente no intervalo $40 \% \mathrm{HR}-80 \% \mathrm{HR}$ (VAN BALEN; VAN GEMERT, 1994; OLIVEIRA, 2016), com temperaturas moderadas. Está também estabelecido que as variações de humidade, nomeadamente os ciclos de humedecimento (por aspersão com água líquida ou exposição a humidades relativas próximas de 100\%) / secagem, contribuem para acelerar a carbonatação (LAGERBLAD, 2006). Nestas condições, na Europa, nas zonas costeiras de clima tipicamente atlântico, por exemplo, ou noutros continentes em zonas quentes e húmidas, a humidade elevada em certas épocas do ano pode atrasar significativamente a carbonatação, enquanto nas zonas mediterrânicas e continentais, durante o verão, ou em zonas de clima desértico, pode haver períodos demasiado secos, que também não favorecem a carbonatação. Nas zonas de clima muito húmido, a adição de pozolanas pode ser particularmente favorável, já que a humidade favorece a reacção pozolânica e atrasa a carbonatação.

As condições climáticas e ambientais na altura da aplicação e nos dias subsequentes influenciam decisivamente o processo de endurecimento, por carbonatação e, sempre que há compostos hidráulicos, também por hidratação. Condicionam, deste modo, a microestrutura e todas as características dos revestimentos de cal. Este fator nem sempre é tido em conta e é uma das fontes de problemas.
Nas argamassas só de cal aérea, a carbonatação proporciona melhor resistência da argamassa à ação da água, porque o carbonato de cálcio é pouco solúvel em água, ao contrário do hidróxido de cálcio; aumenta a resistência mecânica; e origina maior capacidade de proteção à água, uma vez que existe uma redução de porosidade total e também uma redução dos poros grandes (menos poros de raio superior a 0,1 micrómetros) e o surgimento de uma gama de poros muito pequenos (gama de raios de poros de 0,001-0,003 micrómetros) (CIZER et al., 2012; ARANDIGOYEN et al., 2006; LAWRENCE et $a l ., 2007)$. No entanto, a estrutura porosa global da argamassa de cal mantém-se semelhante, ou seja, continua a distinguir-se um pico de poros com diâmetro de cerca de 1 micrómetro, característico da matriz de cal, e um outro de poros grandes, em geral na gama dos 10 a 70 micrómetros, característico da ligação pasta de ligante agregado. Assim, é favorável conseguir uma carbonatação tão profunda quanto possível, mesmo que as camadas internas fiquem apenas parcialmente carbonatadas. No entanto, a carbonatação das camadas superficiais dificulta a progressão do $\mathrm{CO}_{2}$ para as camadas internas, já que os poros inferiores a 0,1 micrómetros não facilitam o transporte da água líquida.

Alguns autores defendem que a permanência de uma determinada proporção de $\mathrm{Ca}(\mathrm{OH})_{2}$ numa argamassa de cal é favorável à sua resistência e durabilidade (MOROPOULOU et al., 2002). Ou seja, é desejável uma boa carbonatação, mas a carbonatação total pode não ser um objetivo.

\section{Aplicação}

A aplicação é um dos fatores mais referidos como sendo influente no desempenho das argamassas de cal. Diz-se frequentemente que a falta de especialização da mão-de-obra inviabiliza o uso com sucesso de revestimentos com base em cal. $\mathrm{Na}$ verdade, o peso do fator humano, e até afetivo, diferencia significativamente as tecnologias artesanais tradicionais, em relação às tecnologias industriais atuais, quer no fabrico da cal, quer na execução dos revestimentos.

Um dos aspetos distintivos dos revestimentos com argamassas de cal é o seu carácter multicamada (VEIGA, 2006; BARBERO-BARRERA et al., 2014) (Figura 2), que favorece significativamente o bom desempenho e a durabilidade destas argamassas. 
Figura 2 - Revestimentos antigos multicamada
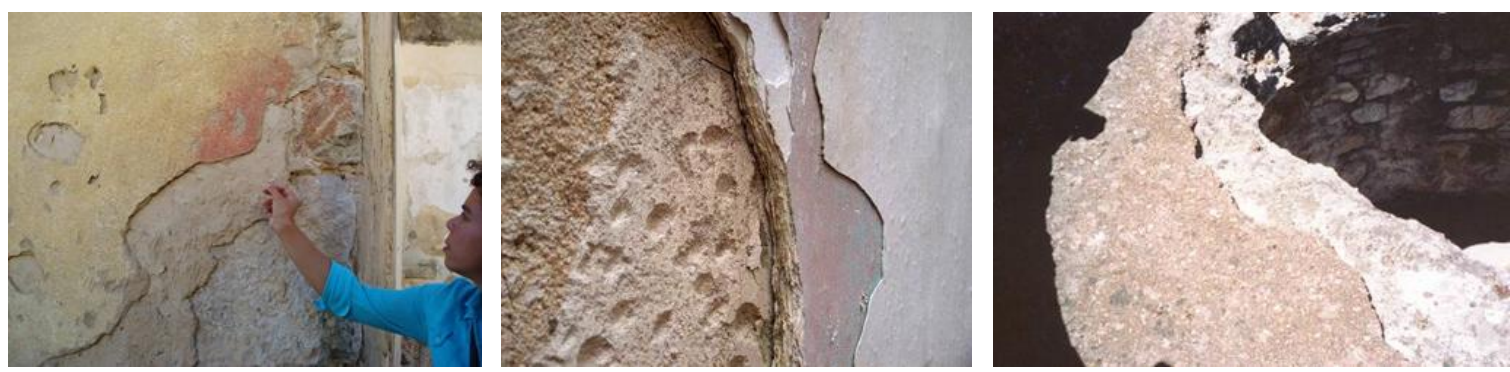

A carbonatação torna-se cada vez mais lenta à medida que se progride para o interior do revestimento ou da junta, porque o $\mathrm{CO}_{2}$ tem que percorrer um caminho mais longo e também porque a camada exterior carbonatada se torna mais compacta, dificultando essa penetração. Portanto, para facilitar a carbonatação em toda a espessura do revestimento de argamassa de cal, a aplicação deve ser feita em várias camadas de baixa espessura, deixando algum tempo de carbonatação entre elas. A técnica multicamada permite também aumentar a capacidade de proteção à água, quer por criar interfaces entre camadas que dificultam a penetração da água, quer por impedir a formação de fissuras contínuas desde a superfície até ao suporte.

Em relação a outros factores ligados à aplicação, como o teor de água de amassadura e o tipo de amassadura e de aplicação, alguns estudos têm sido feitos (CAVACO; VEIGA; GOMES, 2003; BALKSTEN; KLASÉN, 2005; ROSELL et al., 2014), permitindo recomendar alguns procedimentos (VEIGA, 2006):

(a) usar quantidades de água de amassadura bem controladas, conduzindo a uma argamassa bastante consistente; embora mais difícil de aplicar, resulta num revestimento mais compacto, com maior capacidade resistente, menor tendência para fissurar e menor permeabilidade à água;

(b) promover uma mistura perfeita dos constituintes, através de uma amassadura adequada; a amassadura com uma betoneira normal de eixo vertical não é, por si só, a mais indicada para este tipo de argamassa, requerendo pelo menos um procedimento adicional que favoreça uma melhor distribuição de todas as partículas na massa;

(c) apertar bem a massa contra o suporte, ou contra a camada anterior, no momento certo do início do endurecimento, é muito importante já que contribui para garantir maior compacidade e menor fissuração.

(d) aplicar em várias camadas finas: um maior número de camadas, de menor espessura cada uma, diminui as tensões resultantes da retração, reduzindo também a fissuração e melhorando a capacidade de impermeabilização; e

(e) dosear a exposição à radiação solar, que em certa medida facilita a carbonatação da cal e o consequente endurecimento do revestimento, mas, se for em excesso, pode também aumentar a fissuração por dessecação rápida e impedir a dissolução do $\mathrm{CO}_{2}$ necessária à carbonatação.

Os cuidados a ter terão que ser adaptados se se usarem argamassas com pozolanas (aditivos que conferem hidraulicidade à argamassa através de reações com a cal não-carbonatada $\left(\mathrm{Ca}(\mathrm{OH})_{2}\right)$, que se dão ao longo do tempo, na presença de água). Nesse caso, é particularmente importante manter o revestimento húmido durante os primeiros dias, de forma a facilitar as reações pozolânicas; por isso a água de amassadura deve ser em maior quantidade (consistência mais fluida) e o controlo da exposição solar deve ser mais rigoroso (VEIGA; VELOSA; MAGALHÃES, 2009).

Ao contrário do que por vezes se pensa, as argamassas de cal têm retração de secagem elevada e podem, portanto, fissurar logo no início do endurecimento. No entanto, dado que esse endurecimento é lento e que a argamassa se mantem plástica durante muitas horas, a fissuração inicial pode ser colmatada com um novo aperto feito com colher ou com talocha de madeira.

Deste modo, a influência dos múltiplos pequenos cuidados de aplicação e da atenção e cuidado dos aplicadores pode ser decisiva e o fator humano assume um grande relevo.

\section{Durabilidade}

Os fatores de degradação das argamassas são relativamente conhecidos (LANAS; SIRERA; ALVAREZ, 2005; VEIGA, 2007):

(a) sendo materiais muito porosos e com baixa resistência à tração, os fenómenos de gelo/degelo são um dos mecanismos de degradação mais poderosos; 
(b) os sais solúveis, principalmente os mais expansivos ou os que sujeitam a argamassa a mais ciclos dissolução/cristalização, são responsáveis por outro mecanismo muito gravoso;

(c) a água promove a dissolução do hidróxido de cálcio e dificulta a carbonatação (principalmente nas primeiras idades), além de favorecer alguns dos outros mecanismos referidos;

(d) a poluição depositada nas superfícies gera, por dissolução com a água da chuva, ácidos que atacam as argamassa de cal; e

(e) o ataque biológico produz degradação das argamassas, quer pela produção de ácidos, quer pela criação de tensões.

Por outro lado, a carbonatação vai aumentando ao longo do tempo e as ações de dissolução/recristalização do carbonato de cálcio contribuem também para o aumento da compacidade das argamassas, gerando um fenómeno de auto-consolidação (self-healing); assim, se estes mecanismos de "reforço" forem predominantes em relação às ações de degradação, as argamassas de cal poderão ir sempre melhorando ao longo do tempo (BORGES; SANTOS SILVA; VEIGA, 2014; VEIGA et al., 2013). Há poucos estudos de laboratório a longo prazo, mas os resultados existentes mostram incrementos graduais de resistência (MARGALHA, 2010).

Ou seja, nas argamassas de cal é preciso conseguir que os mecanismos de degradação sejam controlados nas primeiras idades (ao longo dos 2 ou 3 anos iniciais) para que a argamassa ultrapasse a fase de maior fragilidade e adquira resistência suficiente para poder evoluir favoravelmente ao longo do tempo. Isso consegue-se com uma boa preparação e aplicação, evitando a fissuração e criando condições para uma carbonatação inicial rápida e em profundidade.

\section{Necessidades de investigação}

Sabe-se que as argamassas de cal são as mais compatíveis e adequadas para conservação de edifícios antigos; sabe-se também que são materiais duráveis; há já um conhecimento técnico e científico consolidado do comportamento destes materiais e dos fatores que influenciam esse comportamento. No entanto, o seu uso em conservação está longe de ser generalizado, podendo mesmo dizer-se que é relativamente raro.

O que falta então saber, ou fazer, para promover o uso generalizado das argamassas de cal nas intervenções de conservação e de reabilitação?
Apontam-se algumas lacunas de conhecimento a colmatar.

Assim, no fator conhecimento técnico-científico, encontram-se as seguintes necessidades:

(a) estudar profundamente os fatores de degradação a curto prazo das argamassas de cal, para poder controlá-los ou evitá-los;

(b) estudar a influência dos fatores locais - tipo de alvenaria, clima, ambiente - na evolução e no comportamento destas argamassas ao longo do tempo;

(c) aprofundar o conhecimento da influência das matérias-primas locais: matéria prima da cal calcário calcítico ou dolomítico, mármore, conchas... - e areias - natureza e granulometria;

(d) definir composições base (incluindo tipo de areia e quantidade de água); e

(e) definir requisitos e regras práticas para cada uso e condições particulares.

No fator humano, já apontado como essencial para o sucesso das argamassas de cal, referem-se também aspetos a desenvolver: apostar na formação a todos os níveis dos intervenientes na conservação e reabilitação. Esta formação:

(a) deve começar pelos técnicos - engenheiros e arquitetos - para que estes materiais e elementos construtivos sejam à partida bem definidos em projeto, com disposições construtivas adequadas; e

(b) deve abranger os aplicadores, que precisam de alguma formação teórica para poderem identificar as questões suscetíveis de originar problemas (tipos de cal, quantidade de água, tempos de secagem, condições climáticas favoráveis, etc.) e de uma formação prática, extremamente importante num trabalho que tem muito de artesanal.

Outro conjunto de aspetos a considerar tem a ver com o fator tempo; é essencial que o planeamento se faça tendo em conta os tempos da cal:

(a) a necessidade de fazer aplicações em condições climáticas apropriadas, tendo portanto folgas de tempo para esperar que não chova e que a humidade e temperatura sejam favoráveis; e

(b) a necessidade de tempos de espera entre aplicações das várias camadas de argamassas de cal e depois dos acabamentos com base em cal.

Faltam, talvez, outras ações, que compete a toda a comunidade interessada ajudar a identificar e a resolver, enquanto ainda há edifícios antigos com argamassas originais para salvar. 


\section{Conclusões}

As argamassas de cal são reconhecidas como as argamassas que oferecem maior compatibilidade com os edifícios antigos, cujas alvenarias e revestimentos tinham originalmente este material como base. Para conseguir a reapropriação do conhecimento necessário à sua utilização em conservação e reabilitação, muita investigação tem sido realizada e muitos estudos técnico-científicos têm sido desenvolvidos. Assim, é hoje possível aceder a muita informação pertinente para a execução e aplicação de argamassas de cal e para evitar a sua degradação.

Os estudos indicam que o traço volumétrico 1:3 confere características equilibradas. Com efeito, traços com menor teor de cal parecem conduzir a menores resistências mecânicas, mas traços com maior teor de cal parecem resultar em porosidades e coeficientes de capilaridade mais elevados. Variados aditivos e adjuvantes podem melhorar algumas características das argamassas de cal, no entanto é necessário escolher produtos adequados e estudar bem as proporções e as condições de cura que os tornam eficazes. Não está provado que o modo de produção e extinção da cal influencie significativamente as características físicas e mecânicas das argamassas, mas apenas resultados a mais longo prazo e em condições de aplicação próximas das reais poderão esclarecer de modo decisivo essa questão. Os agregados usados influenciam decisivamente as características das argamassas de cal, pelo que a escolha cuidada da natureza e da granulometria deste componente é da maior importância. Também o teor de água de amassadura é um fator chave, contribuindo, quando em excesso, para uma porosidade demasiado elevada. A evolução da carbonatação condiciona a resistência da argamassa e está muito relacionada com as condições de cura. Com efeito, as reações químicas que originam a carbonatação e o consequente endurecimento e aumento de resistência das argamassas de cal aérea, requerem humidade mderada, situada aproximadamente no intervalo $40 \%$ HR - $80 \%$ HR e boa exposição ao ar, de modo a garantir contacto com o dióxido de carbono.

São hoje também conhecidos os cuidados necessários na preparação e aplicação das argamassas de cal aérea:

(a) quantidade de água moderada;

(b) mistura completa dos constituintes;

(c) aplicação em várias camadas finas com algum tempo de carbonatação entre elas; (d) (re)aperto da massa contra o suporte ou contra a camada anterior no início do endurecimento; e

(e) dosear a exposição ao sol e à chuva no período inicial após aplicação.

São também conhecidos os principais mecanismos de degradação das argamassas de cal, sendo portanto possível controlá-los: gelo-degelo; dissolução-cristalização de sais solúveis; ação frequente e intensa da água líquida; poluição; ataque biológico.

Com todo este conhecimento científico sobre a cal e as argamassas de cal áerea, deve ser possível aplicá-las com segurança.

Então porque são tão pouco utilizadas? Três conjuntos de aspetos a aprofundar foram identificados, ligados aos seguintes fatores:

(a) fator conhecimento científico, principalmente ao nível das condições locais: condições climáticas, características das alvenarias e diferentes naturezas dos materiais de base para execução das argamassas;

(b) fator humano: a formação dos técnicos e a formação teórica e prática dos aplicadores é um aspeto essencial, dadas as diferenças em relação aos materiais mais modernos e a maior necessidade de cuidado no pormenor; e

(c) fator tempo, em particular relativamente à necessidade do planeamento das intervenções tendo em conta os tempos necessários ao materiais de cal, mais longos que os dos materiais de cimento:maturação, aplicação em várias camadas e com aperto do material, carbonatação lenta.

Existirão talvez mais lacunas e fatores a considerar, cuja identificação se remete para toda a comunidade de interessados na cal.

Ainda uma pergunta final: que ações implementar para colmatar as lacunas e atingir o objetivo de aplicar de facto as argamassas de cal?

\section{Referências}

ALMEIDA, L. et al. Characterization of Renders From Buildings Awarded With Lisbon's Valmor Prize of Architecture (1902 - 2002): state of conservation and contributions for preservation. In: PROHITECH'17, 3., Lisboa, 2017. Proceedings... Lisboa, 2017.

ARANDIGOYEN, M. et al. Variation of Microstructure With Carbonation in Lime and Blended Pastes. Applied Surface Science, v. 252, p. 7562-7571, 2006. 
ARIZZI, A. et al. Mechanical Evolution of Lime Mortars during the Carbonation Process.Key Engineering Materials, v. 465, p. 483-486, 2011.

BALKSTEN, K.; KLASÉN, K. The Influence of Craftmanship on the Inner Structures of Lime Plasters. Delft: RILEM Workshop, 2005.

BARBERO-BARRERA, M. M. et al. Lime Render Layers: an overview of their properties. Journal of Cultural Heritage, v. 15, p.326-330, 2014.

BENTUR, A. Cementitious Materials: nine millennia and a new century: past, present, and future. Journal of Materials in Civil Engineering, v. 14, n. 1, p. 2-22, 2002.

BORGES, C.; SANTOS SILVA, A.; VEIGA, R. Durability of Ancient Lime Mortars in Humid Environment. Construction and Building Materials, v. 66, p. 606-620, 2014.

BORSOI, G.et al.Microstructural and PhysicalMechanical Analysis of the Performance of Nanostructured and Other Compatible Consolidation Products For Historical Renders.Materials and Technology Magazine (Materili in Tehnologije), v. 46, p.93-97, 2012.

CAVACO, L.; VEIGA, M. R.; GOMES, A.Render Application Techniques For Ancient Buildings. In: INTERNATIONAL SYMPOSIUM ON BUILDING PATHOLOGY, DURABILITY AND REHABILITATION, 2., Lisboa, 2003.Proceedings... Lisboa, 2003.

CAZALLA, O. et al. Aging of Lime Putty: effects on traditional lime mortar carbonation. Journal of the American Ceramic Society, v. 83, n. 5, p. 1070-1076, 2002.

CIZER, Ö. et al. Real-Time Investigation of Reaction Rate and Mineral Phase Modifications of Lime Carbonation. Construction and Building Materials, v. 35, p. 741-751, 2012.

DI BELLA, G. et al.Effects of Natural Fibres Reinforcement in Lime Plasters (kenaf and sisal vs. Polypropylene). Construction and Building Materials, v. 58, p.159-165, 2014.

DURAN, A. et al. Long-Term Mechanical Resistance and Durability of Air Lime Mortars With Large Additions of Nanosilica. Construction and Building Materials, v. 58, p. 147-158, 2014.

FARIA, P.; HENRIQUES, F.; RATO, V. Comparative Evaluation of Lime Mortars For Architectural Conservation. Journal of Cultural Heritage, v. 9, p. 338-346, 2008.
FARIA-RODRIGUES, P. Argamassas de Revestimento Para Alvenarias Antigas: contribuição para o estudo da influência dos ligantes. Lisboa, 2004. Tese (Doutorado em Engenharia Civil) - Universidade Nova de Lisboa, Lisboa, 2004.

FRAGATA, A.; VEIGA, M. R. Air Lime Mortars: the influence of calcareous aggregate and filler addition. Materials Science Forum, v. 636/637, p. 1280-1285, 2010.

GAMEIRO, A. et al. Hydration Products of LimeMetakaolin Pastes at Ambient Temperature With Ageing. Thermochimica Acta, v. 535, p. 36-41, may 2012.

GILLMORE, Q. Limes Hydraulic Cement and Mortars. [S.1.]: Wexford College Press, 2000.

GUERREIRO, C.; HENRIQUES, F.; PINTO, A. Análise Comparativa de Argamassas de Cal Aérea, Medianamente Hidráulicas e de Ligantes Mistos Para Rebocos de Edifícios Antigo. In: CONGRESSO NACIONAL DE ARGAMASSAS DE CONSTRUÇÃO, 2., Lisboa, 2007. Anais... Lisboa, 2007.

HANSEN, E. F. et al. Effects of Ageing on Lime Putty. In: INTERNATIONAL RILEM WORKSHOP: HISTORIC MORTARS: CHARACTERISTICS AND TESTS, 2000. Proceedings... 2000.

HENRIQUES, F. Challenges and Perspectives of Replacement Mortars in Architectural Conservation. In: GROOT, C. (Ed.). International Rilem Workshop on Repair Mortars For Historic Masonry. Delft: RILEM, 2005.

LAGERBLAD, B. Carbon Dioxide Uptake During Concrete Life, Sate of the Art. Stockholm: Swedish Cement and Concrete Research Institute, 2006.

LANAS, J.; ALVAREZ, J. I. Masonry Repair Lime-Based Mortars: factors affecting the mechanical behavior. Cement and Concrete Research, v. 33, p. 1867-1876, 2003.

LANAS, J.; SIRERA, R.; ALVAREZ, J. I. Compositional Changes in Lime-Based Mortars Exposed to Different Environments.

Thermochimica Acta, v. 429, n. 2, p. 219-226, 2005.

LANAS, J.; SIRERA; R.; ALVAREZ, J. I. Study of the Mechanical Behaviour of Masonry Repair Lime-Based Mortars Cured and Exposed Under Different Conditions. Cement and Concrete Research, v. 36, p. 961-970, 2006. 
LAWRENCE, R. M. H. A Study of Carbonation in Non-Hydraulic Lime Mortars. PhD Thesis, University of Bath, 2006.

LAWRENCE, R. M. H. et al. Effects of Carbonation on the Pore Structure of NonHydraulic Lime Mortars. Cement and Concrete Research, v. 37, n. 7, p. 1059-1069, 2007.

LIGUORI, B.; CAPUTO, D.; LUCOLANO, F. Fiber-Reinforced Lime-Based Mortars: effect of zeolite addition. Construction and Building Materials, v. 77, p. 455-460, 2015.

MAGALHÃES, A. C.; VEIGA, M. R.

Caracterización Física y Mecánica de los Morteros Antiguos: aplicación a la evaluación del estado de conservación. Materiales de construcción, v. 59, p. 61-77, 2009.

MARGALHA, G. et al. Microstructural Changes of Lime Putty During Aging. Journal of Materials In Civil Engineering, v. 25, n. 10, p. 1524-1532, 2013a.

MARGALHA, G. et al. Traditional Methods of Mortar Preparation: the hot lime mix method. Cement \& Concrete Composites,v. 33, p. 796804, 2011.

MARGALHA, M. G.et al. A Influência do Teor de Cal em Pasta em Argamassas. In: SEMINÁRIO LIMECONTECH - CONSERVAÇÃO E DURABILIDADE DE REVESTIMENTOS HISTÓRICOS - TÉCNICAS E MATERIAIS COMPATÍVEIS, Lisboa, 2013. Proceedings... Lisboa: LNEC, 2013b.

MARGALHA, M. G. Ligantes Aéreos Minerais: processos de extinção e o factor tempo na sua qualidade. Lisboa, 2010. Tese (Doutorado) Universidade de Lisboa, Lisboa, 2010.

MARGalha, M. G. O Uso da Cal em Argamassas no Alentejo. Évora, 1997. Dissertação (Mestrado em Recuperação do Património Arquitetónico e Paisagístico) Universidade de Évora, Évora, 1997.

MARQUES, S. F. et al.Study of Rehabilitation Mortars: construction of a knowledge correlation matrix. Cement and Concrete Research, v. 36, p. 1894-1902, 2006.

MOROPOULOU, A. et al. Advanced Byzantine Cement Based Composites Resisting Earthquake Stresses: the crushed brick/lime mortars of Justinian's Hagia Sophia.Construction and Building Materials, v. 16, p. 543-552, 2002.
OLIVEIRA, M. A Multi-Physics Approach Applied to Masonry Structures With NonHydraulic Lime Mortars. Minho, 2016. Tese (Doutorado em Engenharia de Estruturas) Universidade do Minho, Minho, 2016.

PAPAYIANNI, I.; STEFANIDOU, M. Durability Aspects of Ancient Mortars of the Archeological Site of Olynthos.Journal of Cultural Heritage, v. 2, n. 8, p. 193-196, 2007.

PASCOAL, P. et al. Consolidation and Chromatic Reintegration of Historical Renders With LimeBased Pozzolanic Products. Studies in Conservation, v. 60, n. 5, p. 321-332, 2015.

PAVLÍK, V.; UŽÁKOVÁ, M. Effect of Curing Conditions on the Properties of Lime, LimeMetakaolin and Lime-Zeolite Mortars.

Construction and Building Materials, v. 102, p. 14-25, 2016.

PERONI, S. et al.Lime Based Mortars For the Repair of Ancient Masonry and Possible Substitutes. Rome: ICCROM, 1981.

POPOVICS, S. Concrete Materials: properties specifications and testing. $2^{\text {nd }}$. ed. Elsevier, 1992.

RAMALHO, C. A Resistência Mecânica e a Porosidade das Argamassas Bastardas Com Baixo Teor de Cimento. Évora, 2013. Dissertação (Mestrado em Engenharia Civil) - Universidade de Évora, Évora, 2013.

RATO, V. Influência da Microestrutura Morfológica no Comportamento de Argamassas. Lisboa, 2006. Tese (Doutorado em Engenharia Civil) - Universidade Nova de Lisboa, Lisboa, 2006.

RODRIGUEZ-NAVARRO, C.; HANSEN E. F.; GINELL, W. Calcium Hydroxide Crystal Evolution Upon Aging of Lime Putty. Journal of the American Ceramic Society,v. 81, n. 11, p. 3032-3034, 1998.

ROMAGNOLI, M.; RIVASI, M. R. Optimal Size Distribution to Obtain the Densest Packing: a different approach. Journal of the European Ceramic Society, v. 27, p. 1883-1887, 2007.

ROSELL, J. R. et al. Influence of the Traditional Slaking Process on the Lime Putty Characteristics. Construction and Building Materials, v. 55, p. 423-430, 2014.

RUA, H. The Ten Books of Architecture by Vitrúvius. Lisboa, IST, 1998.

SANTOS A. R. et al. A Influência das Areias no Desempenho Mecânico das Argamassas de Cal. Lisboa, 2015. 
SILVA, A. S. et al. Mineralogical and Chemical Characterization of Historical Mortars From Military Fortifications in Lisbon Harbour (Portugal). Environmental Earth Sciences, v. 63, p. 1641-1650, 2011.

STEFANIDOU, M.; PAPAYIANNI, I. The Role of Aggregates on the Structure and Properties of Lime Mortars. Cement \& Concrete Composites, v. 27, p. 914-919, 2005.

VAN BALEN, K.; VAN GEMERT, D. Modelling Lime Mortar Carbonation. Materials and Structures, v. 27, p. 393-398, 1994.

VEIGA, M. R. Arquitectura Ibérica. Reabilitação, n. $12,2006$.

VEIGA, M. R. Conservação e Reparação de Revestimentos de Paredes de Edifícios Antigos: métodos e materiais. Lisboa: LNEC, 2007.

VEIGA, M. R. et al.Characterization of Renders and Plasters From a 16th Century Portuguese Military Structure: chronology and durability.

Restoration of Buildings and Monuments, v. 19, n.4, p. 223-238, 2013.

VEIGA, M. R. et al. Lime-Based Mortars: viability for use as substitution renders in historical buildings. International Journal of

Architectural Heritage, v. 4, n. 2, p. 177-195, 2010.

VEIGA, M. R.; VELOSA, A.; MAGALHÃES, A. C. Experimental Applications of Mortars With Pozzolanic Additions: characterization and performance evaluation. Construction and Building Materials, v. 23, n. 1, p. 318-327, 2009.
VELOSA, A. L. et al. Characterization of Roman Mortars From Conímbriga With Respect to Their Repair. Materials Characterization, v. 58, p. 1208-1216, 2007.

VELOSA, A. L.; VEIGA, M. R. Argamassas do Património Histórico: conhecer para conservar e reabilitar. In: CONGRESSO INTERNACIONAL SOBRE PATOLOGIA E REABILITAÇÃO DE ESTRUTURAS, 12.,Porto, 2016. Anais... Porto, 2016.

VELOSA, A.; VEIGA, M. R. The Use of Pozzolans as Additives in Lime Mortars For Employment in Building Rehabilitation. In: INTERNATIONAL SEMINAR "HISTORICAL CONSTRUCTIONS 2001", Guimarães, 2001. Proceedings... Guimarães: Universidade do Minho, 2001.

WALKER, R.; PAVIA, S.; MITCHELL, R. Mechanical Properties and Durability of HempLime Concretes. Construction and Building Materials, v. 61, p. 340-348, 2014.

\section{Agradecimentos}

Este trabalho insere-se no Projeto PTDC/EPHPAT/4684/2014 "DB-Heritage - Base de dados de materiais de construção com interesse histórico e patrimonial" financiado pela Fundação para a Ciência e a Tecnologia (FCT) de Portugal e no Projeto do LNEC LNEC PRESERVe Preservação de revestimentos do Património construído com valor cultural: identificação de riscos, contributo do saber tradicional e novos materiais para conservação e proteção. A autora agradece também a todos os colegas participantes destes projetos, cujo trabalho tem contribuído para consolidar conhecimentos nesta área.

Maria do Rosario Veiga

Departamento de Edifícios | Laboratório Nacional de Engenharia Civil | Av. do Brasil, 101 | 1700-066 | Libosa - Portugal | Tel.: +351 2184-43668 | E-mail: rveiga@lnec.pt

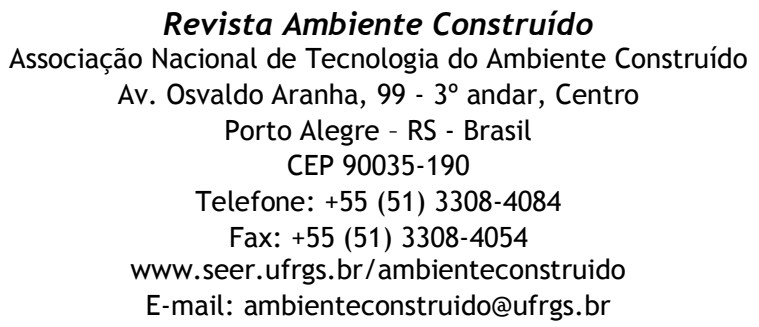

